\title{
Case Study on Tacit Knowledge Management Systems within X Company*
}

\author{
Jiangping Wan ${ }^{1,2}$, Ming Zeng ${ }^{1}$, Yahui Zhu' ${ }^{1}$ \\ ${ }^{1}$ School of Business Administration, South China University of Technology, Guangzhou, China \\ ${ }^{2}$ Institute of Emerging Industrialization Development, South China University of Technology, Guangzhou, China \\ Email: scutjsp@126.com, zm656690@qq.com, zhuyahui0819@qq.com
}

Received February 12, 2013; revised March 29, 2013; accepted April 6, 2013

Copyright (c) 2013 Jiangping Wan et al. This is an open access article distributed under the Creative Commons Attribution License, which permits unrestricted use, distribution, and reproduction in any medium, provided the original work is properly cited.

\begin{abstract}
Case study on tacit knowledge management system within X company includes the design of tacit knowledge management system (the recognition and acquisition of tacit knowledge), mechanisms (the factor analysis for the transition and sharing of tacit knowledge) and implementation (the sharing enterprise culture build, the effective incentive mechanism construct and the organization structure design). The evaluation system is established based on critical success factors (the recognition capability, the sharing standard, the sharing mechanism of tacit knowledge). The purpose of study is to improve tacit knowledge management system within enterprise.
\end{abstract}

Keywords: Explicit Knowledge; Tacit Knowledge; Knowledge Conversion; Tacit Knowledge Management Systems; Case Study

\section{Introduction}

Michael Polanyi divided knowledge into tacit knowledge and explicit knowledge [1]. Tacit knowledge exists in human brains, which is the knowledge that people don't know, in other words people don't know what they know. Verna Allee thought that tacit knowledge which exists in individuals is private and has its own special background, and it also depends on experience, intuition and discernment [2]. Nonaka figured that organizations create and make use of knowledge via the interaction of tacit knowledge and explicit knowledge, which is called knowledge conversion process [3].

$\mathrm{X}$ company is a global management consulting, technology services and outsourcing company, with approximately 259,000 people serving clients in more than 120 countries. X company, which owns unparalleled experience, comprehensive capabilities across all industries and business functions, and extensive research on the world's most successful companies, collaborates with clients to help them become high performance businesses and governments.

$\mathrm{X}$ company has conducted business more than twenty years in the greater China region, which locates in Bei-

\footnotetext{
*This research was supported by Key Project of Guangdong Province Education Office (06JDXM63002), NSF of China (70471091), and QualiPSo (IST-FP6-IP-034763).
}

jing, Shanghai, Dalian, Chengdu, Guangzhou, Hong Kong and Taipei. X company, an expert for performance improvement, helps customers determine strategy, optimize the process, integrate system, import innovation, enhance the overall competitive advantage, thus achieves great excellent performance. Its senior managers also carry out successful knowledge management practice within its interior, sharing knowledge has become the long-standing culture while X company helps customers manage knowledge effectively. The success for X company largely benefits from its strong knowledge management system.

This paper is organized in the following: Section 2 is a literature review, including Nonaka's framework of knowledge creation mechanisms, the concept of knowledge conversion, and knowledge management in software process improvement (SPI). Section 3 is tacit knowledge management systems (TKMS) design. Section 4 is TKMS mechanisms. Section 5 is TKMS implementation. Section 6 is TKMS evaluation. Section 7 is conclusion.

\section{Literature Review}

Language is an excellent example of tacit knowledge: native speakers of a language are often unable to articulate the grammatical and syntactic rules governing it. Tacit knowledge contributes to the "stickiness" of infor- 
mation required for problem-solving, making it difficult for others to gather, transfer, and utilize. The difficult to codify nature of tacit knowledge contributes to difficult to imitate capabilities that may provide competitive advantage to the organization. Success of process improvement projects depends on the capture of both explicit and tacit types of knowledge [4].

The concept of "tacit knowledge" is a cornerstone in organizational knowledge creation theory and covers knowledge that is unarticulated and tied to the senses, movement skills, physical experiences, intuition, or implicit rules of thumb. Knowledge of wine tasting, crafting a violin, or interpreting a complex seismic printout of an oil reservoir is well-known examples of tacit knowledge. Tacit knowledge differs from "explicit knowledge" that is uttered and captured in drawings and writing. For example, knowledge of a solution to a differential equation is explicit knowledge. The concept of "knowledge conversion” explains how tacit and explicit knowledge interact along a continuum [4].

Nonaka's framework [3] provides a rationale for the use of knowledge-creation practices to generate group knowledge by engaging individual team members in process improvement projects. The framework depicts the process of knowledge creation as cycles of conversions between two types of knowledge-explicit, and tacit (Figure 1). It is worthwhile to note that this classification of knowledge as either explicit or tacit is one of two prominent classifications in the knowledge management literature (Table 1 provides a brief overview of different classifications of knowledge creation efforts [5]). Explicit knowledge is codified and documented, and its transfer can take place in impersonal ways-for instance, through written instructions and diagrams. Tacit knowledge is knowledge that is difficult to articulate, especially in terms of cause-effect relationships.

Knowledge transfer model of software process improvement (SPI) and the conceptual framework of influencing factors are established in [6]. The model includes five elements which are knowledge of transfer, sources of knowledge, recipients of knowledge, relationship of transfer parties, and the environment of transfer.

The conceptual framework includes ten key factors which are ambiguity, institutionalization, transfer willingness, capacity of impartation, capacity of absorption, incentive mechanism, culture, technical support, trust and knowledge distance. The knowledge creation effective factors were found in both necessary elements for stimulus of knowledge creation and the key influencing factors of software project success [7]. The knowledge creation effective factors in requirement development project are clarified through deeply interviewing the software enterprises in Guangdong province as well as other corporate

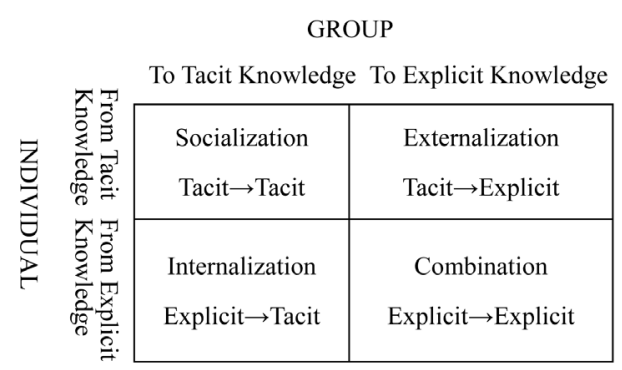

Figure 1. Nonaka's framework of knowledge-creation mechanisms.

Table 1. Selected classifications of knowledge creation mechanisms.

\begin{tabular}{ccc}
\hline Author(s) & Year & Knowledge creation mechanisms \\
\hline Argyris & 1977 & $\begin{array}{c}\text { Single \& double loop learning } \\
\text { Combination, internalization, } \\
\text { socialization \& externalization }\end{array}$ \\
$\begin{array}{c}\text { Nonaka } \\
\text { Kogut and } \\
\text { Zander }\end{array}$ & 1991 & $\begin{array}{c}\text { Operational \& conceptual } \\
\text { Spender }\end{array}$ \\
$\begin{array}{c}\text { Nahapiet and } \\
\text { Ghoshal }\end{array}$ & 1996 & $\begin{array}{c}\text { Capturing individual and } \\
\text { organizational knowledge }\end{array}$ \\
\hline
\end{tabular}

information departments. Knowledge creation theory of Nonaka is appropriate for analyzing knowledge creating of software requirement development (SRD). The issue of this research is exported: how to improve SRD with knowledge creation theory? And it includes three subissues: 1) What factors are impacting SRD in the view of knowledge creation theory? 2) What do enable knowledge flow during SRD? 3) How can we guide SRD by using knowledge creation theory? Case study findings include [8]: 1) It can facilitate the implementation of the project to have the necessary diversity of the project team; 2) The introduction of experts on requirement can achieve the transformation of knowledge effectively, thus helping to carry out the project; 3) Methodology and related technologies are important. A knowledge model for SPI project based on knowledge creation theory and its twenty-four measurement items are developed in [9], and two hypothesizes about the interaction of explicit knowledge and tacit knowledge in SPI are proposed. Eleven factors are extracted through statistical analysis. Three knowledge creation practices for capturing tacit knowledge contribute greatly to SPI, which are communication among members, crossover collaboration in practical work and pair programming. Two knowledge creation practices for capturing explicit knowledge have significant positive impact on SPI, which are integrating project document and on the job training. 


\section{Tacit Knowledge Management Systems Design}

$\mathrm{X}$ company strengthens enterprise tacit knowledge management to convert the enterprise knowledge assets into tangible assets for sustainable competitive advantage. It is necessary to manage the tacit knowledge that we must have a explicit understanding on both the purpose and function of tacit knowledge management for recognition and acquirement tacit knowledge.

\subsection{The Purpose, Function of Tacit Knowledge Management}

Tacit knowledge management can achieve the following purpose and function within an enterprise: 1) Enhance the enterprise's strain and innovation capacity. Tacit knowledge management improves enterprise organization's strain and innovation capacity with the knowledge sharing and collective wisdom; 2) Prevent the loss of enterprise's core knowledge. Tacit knowledge management can prevent a heavy loss that enterprise's knowledge staff or technician leaving office; 3) Improve the organization efficiency. With obtaining and sharing the best experience, enterprise can shorten the operation time and minimize the repeated work, so as to improve the organization efficiency.

\subsection{The Recognition of Tacit Knowledge}

It is necessary to recognize knowledge for managing tacit knowledge in $\mathrm{X}$ company. It should be to make internal tacit knowledge transparent, find out the knowledge which can create the most value, where and who needs these knowledge, who controls these knowledge, then describe the relationship between the personnel, work and tacit knowledge, it is necessary for achieving the communication and sharing of tacit knowledge.

\subsubsection{The Classification of Tacit Knowledge}

$\mathrm{X}$ company classifies the tacit knowledge as follow: 1) It can be divided into practice, impart and innovative according to the different approach which the knowledge staff obtains tacit knowledge; 2) It can be divided into encoding, not easy coding and can't coding according to the degree of coding; 3) It can be divided into individual, team and enterprise according to the different degree that group locates in; 4) It can be divided into apparent, transitional, matured according to the cognition degree of tacit knowledge owner to tacit knowledge and the innovated degree of tacit knowledge.

\subsubsection{Enterprise Knowledge Structure Chart Build}

Knowledge structure chart refers to a chart in a method refine knowledge based from big to small, from thick to thin, from general to professional, in the form of tree hierarchical structure, decomposed the organize knowledge of layers. The method of building enterprise knowledge structure chart is: first of all, enterprise managers should determine enterprise's overall strategic goals according to inner and outer environment. Then, the enterprise's overall goal is deeply analysed, the overall goal into different points target is decomposed, and the corresponding business process is recognized. Next, all knowledge are recognized which needed during realizing each business process, classify the knowledge according to attributes levels. Last, it is to excavate the identified knowledge with directional mining method on the basis of classification (Figure 2).

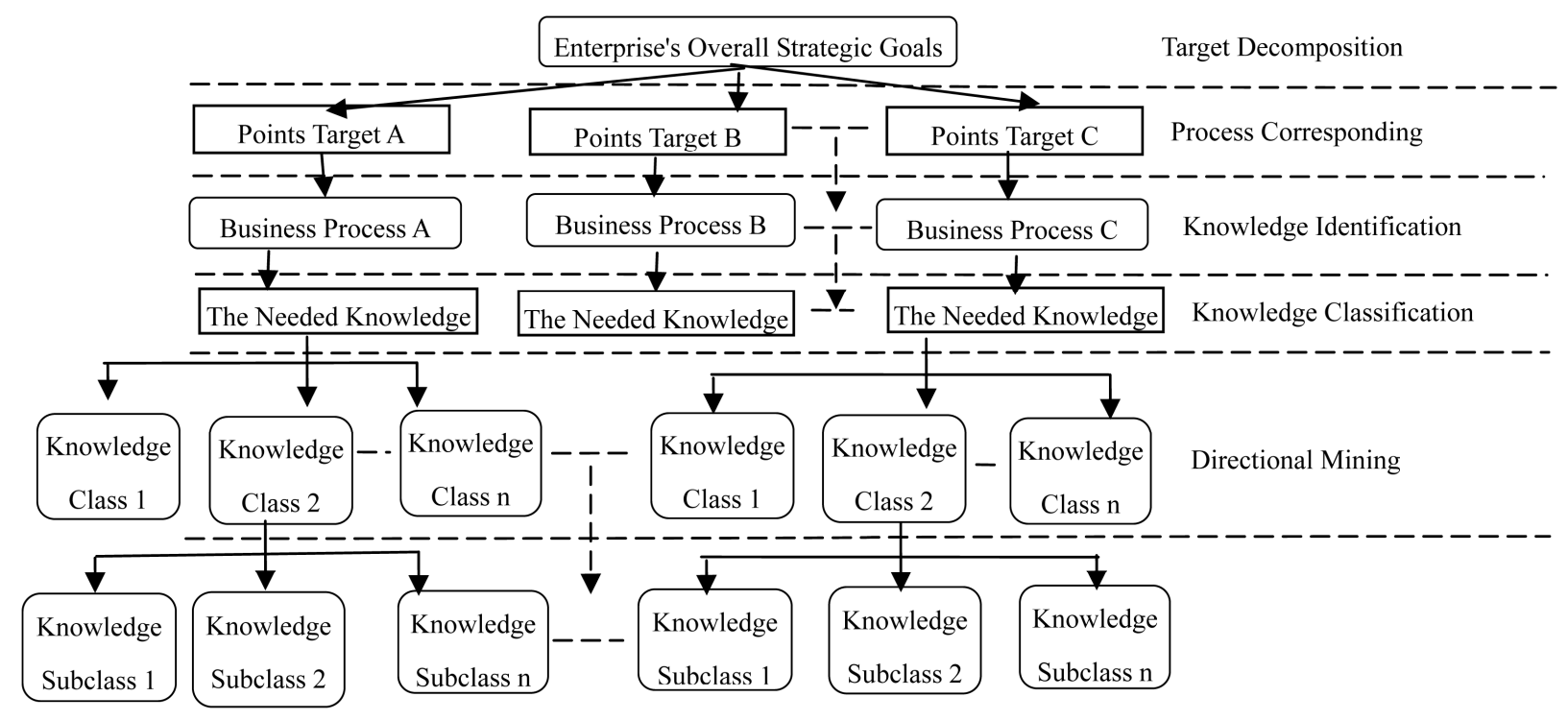

Figure 2. X company knowledge structure chart. 


\subsubsection{Expert Knowledge Map Build}

The building process of expert knowledge map for $\mathrm{X}$ company is: The recognition of enterprise knowledge experts; the selection of experts; the classification and recognition of knowledge experts; establish a search engine of knowledge experts; expand expert knowledge map's content, improve in the repeated evaluation; precipitate experts' tacit knowledge (Figure 3).

\subsection{Tacit Knowledge Obtain}

$\mathrm{X}$ company acquires apparent tacit knowledge through on-the-scene observation, experience, imitation and crowd test; acquires the matured tacit knowledge through the man-machine auxiliary experiment to speed up the tacit knowledge refinement, finds problems and tacit knowledge kernel with the help of computer through the ideas of the simulation system with low cost; we can obtain by on-the-scene observation, experience, mentoring with statistics for the transient state of tacit knowledge.

\section{Tacit Knowledge Management Systems Mechanism}

\subsection{The Factor Analysis of Affecting Tacit Knowledge Transition and Sharing}

4.1.1. Analysis in the Perspective of Human Nature Tacit knowledge owners usually have forestall and monopoly psychology, leading tacit knowledge difficult to automatic communicate and transform, plus the unfair phenomenon of domestic enterprises "knowledge transaction” widespread, it accelerates staff and organization

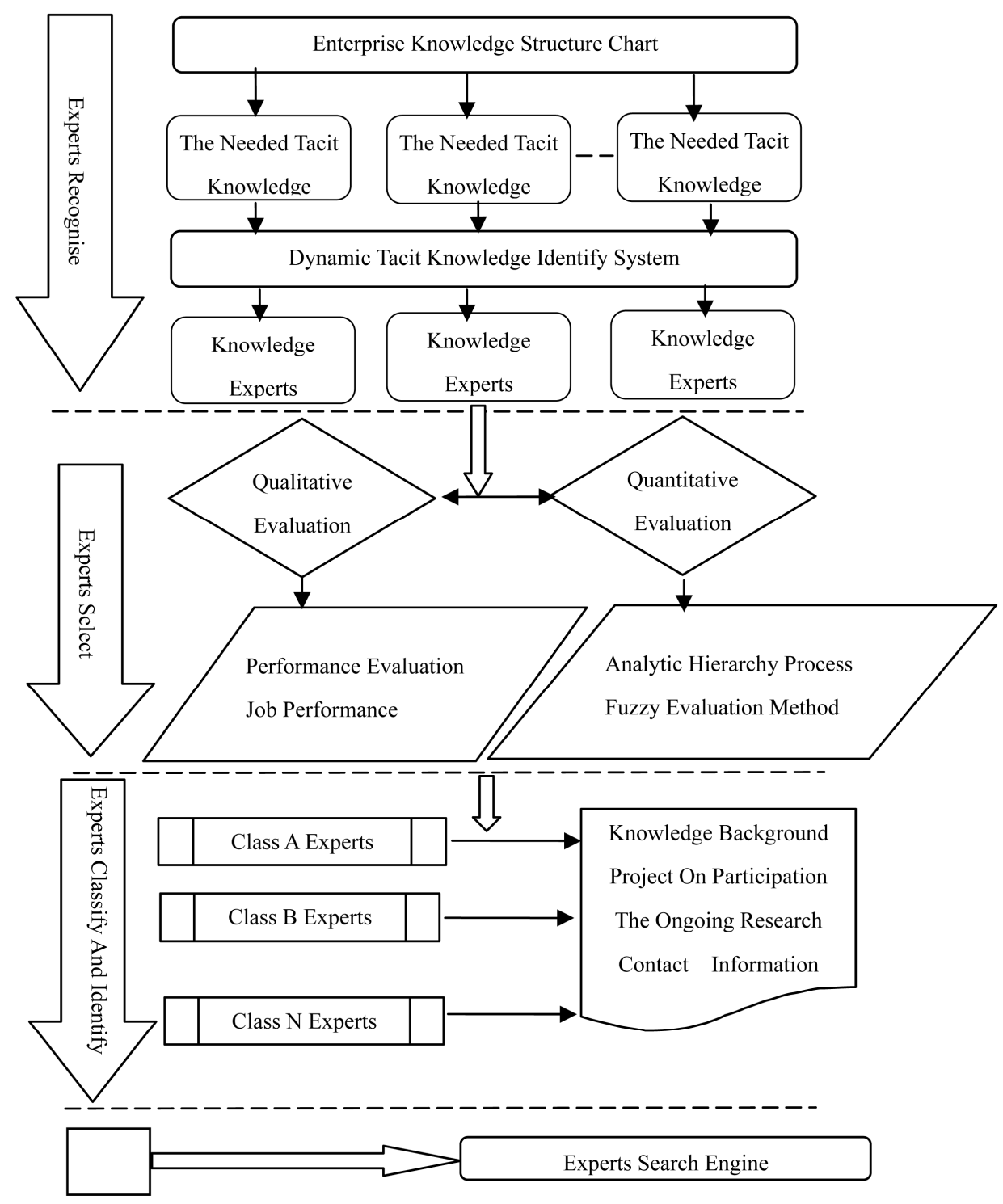

Figure 3. X company expert knowledge map. 
owned tacit knowledge to protect their own intellectual property rights and also further intensifies this kind of psychology. Knowledge receiver have conflicted psychology. The reasons are primary in the following: the competitive concept is not clear, the "hide privacy" psychology, "knowledge island" phenomenon.

4.1.2. Analysis from Perspective of Enterprise Culture At present there is a common misunderstanding within the organization, such as the solutions provided by senior members are better than the ones provided by primary members. The organization should avoid measuring the quality of knowledge by position, it should be judged with the knowledge of the contribution and fitness. Moreover, the team members lack direct dialogue space, many organizations only pay more attention to the infrastructure construction, but ignore to create a good dialogue environment for team members, thus appear the situation that the members of the organization have the desire of communication but without communication place. Moreover, team members lack necessary trust between each other. The basis of knowledge transition is credit. Credit refers to "believe" or "trust" according to the view of Davenport. Because different people have different evaluation about the significance, value, meanness of knowledge, the conclusion may be different, so the team members have different sense of approval for the same view between each other, inevitably lack of trust. Finally, team members lack common language. Communication between both have a big difference with the knowledge basis and communication barriers, it is also difficult to promote tacit knowledge transform and the realization of enterprise knowledge sharing.

\subsubsection{Analysis from the Perspective of Characteristics of the Knowledge Itself}

First of all, knowledge itself has unique scarcity. Secondly, tacit knowledge has media nonverbal characteristics. One of the characteristics for tacit knowledge is existing in the form of the language, secondly, the needed time of study also becomes a factor interfered with the propagation of tacit knowledge, the distance also produces influence and difficulty for the propagation of tacit knowledge. Thirdly, tacit knowledge has unconscious characteristics, first of all, it often makes people ignore the existence of tacit knowledge, secondly, from the perspective of personal use, we usually don't need to make it clarify and consume a large time for only using the tacit knowledge; many expression form of tacit knowledge are thought no value. Some individuals who own the tacit knowledge of unique value usually don't want to transfer and share. Finally, tacit knowledge as a kind of capability can bring value to a person.

\subsubsection{Analysis from the Perspective of Management Institution}

First of all, enterprise tacit knowledge flow does not adapt to enterprise organization structure. The traditional organization structure uses the pyramid hierarchical organization structure, although this kind of organization structure improves the labor productivity to some extent, it will appear the following disadvantages with the development of society: it is difficult for knowledge and information communication, it is difficult staff creativity, it is difficult to adapt the changeable environment quickly. Moreover, without organization incentive system, it is difficult to measure knowledge sharing performance effectively. People are competitive inherently, they also show self-satisfaction for owing the knowledge others lacked, and even keep a secret, make themselves become the owner of the scarce resources and have the superiority. It is difficult for X company let employees share their knowledge. The traditional organization performance appraisal system doesn't put the employee's knowledge contribution in an important position which should be. There are incentive systemic problems, the adaptability of the incentive problem, the effectiveness of the incentive problem, incentive innovation question and other kinds of problems incentive system in fact within enterprise.

\subsection{Sharing Tacit Knowledge}

\subsubsection{Ways for Sharing Tacit Knowledge}

$\mathrm{X}$ company realizes the sharing of tacit knowledge as follow: 1) Establish community practice. When people have a reason to work together, they will share stories and lessons they learned, they impart their practical knowledge each other; 2) Master trains an apprentice. "Master trains an apprentice" activities make the staff have the opportunity to absorb and digest experience and broad their views from industry experts; 3) Personnel rotation. According to the generally determined deadline of enterprise planned, let staffs rotate as different working practice; 4) Strong connected cross-functional team. Knowledge workers from different functional departments work in the same team work, it makes them share their tacit knowledge, and when the team complete the task and dismiss, different functional departments' employees can also bring the complementary tacit knowledge back to their departments, further promoting and applying; 5) Construct case library. The construction process of the case library includes four phases for describing, storage, sharing and innovation. In the describing phase, experts can describe the safety knowledge clearly through many kinds of form either elaborating the specific process or describing and demonstrating by some tools at the same time. In the storage phase, or- 
ganization should gather, select, classify, sort and storage to the organizational case library with the numerous secure knowledge, so the past work experiences of organization and decision-making cases can become repeated using resources. In the sharing phase, the organization provide case sharing platform in the internal organization, so that employees can extract the ways of solving related problems quickly through the case study, not all start from all over again, and avoid the waste of resources. In the innovation phase, employees blend tacit knowledge acquired from case in its own knowledge system through integration and internality, and apply knowledge in the actual work practice, arouse a new valuable tacit knowledge; 6) Establish experts group. Organization should strengthen the effective supervision and support during assembling experts group to make sure that questions can get a satisfactory answer asked by employees; 7) Keep experience communication conferences. In the experience communication conferences, the content of the employees expressed bases on their own knowledge background, every employee submit their knowledge in the process, understand and learn other people's knowledge, so as to realize the knowledge sharing; 8) Establish interest groups. Group determines the project based on the analysis of enterprise internal question; 9) Establish electronic network. It is an important channel which making the knowledge sharing both sides get rid of space, time limit and ignoring the organization internal hierarchy relationship to realize the knowledge sharing to a certain extent.

\subsubsection{Technology Platform of Sharing Tacit Knowledge}

It should solve two basic questions for realizing knowledge sharing. First, construct the enterprise information network which covers all business activities of the enterprise and guarantee that the enterprise has a smooth physical channel in each information release point and information collection point in the complex survival environment; Second, the application software systems should be developed to meet the needs of enterprise (Figure 4).

\subsubsection{Institution of Sharing Tacit Knowledge}

The institution of sharing tacit knowledge in X company includes the following aspects: the institution of knowledge classification and standardization, the institution of knowledge document accumulation and update, the institution of the internalization of external knowledge, the institution of intellectual property rights protection.

The institution of knowledge classification and standardization refers to that the classification of enterprise knowledge can not only be in a accordance with post and professional classification, but also can be in accordance

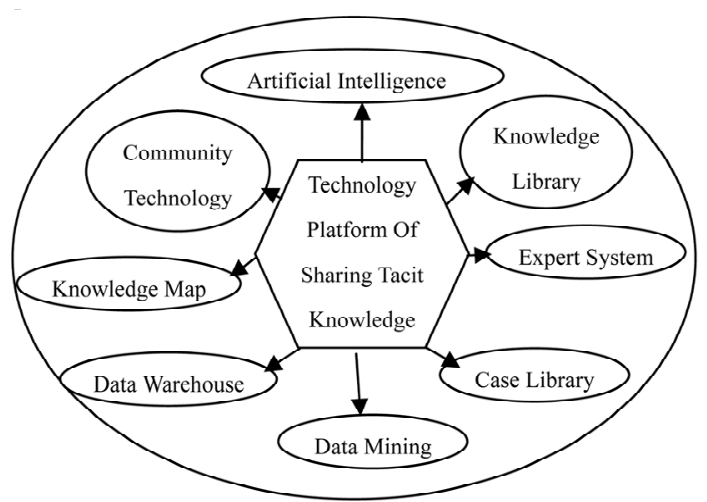

Figure 4. Technical platform of sharing tacit knowledge within X company.

with the local knowledge and global knowledge, routine knowledge and exception knowledge in order to make the knowledge enterprises' tacit knowledge share and apply better. Local knowledge refers to the knowledge sharing in a team, a department of enterprise, and global knowledge refers to knowledge sharing in all the departments of enterprise. Routine knowledge refers to knowledge that can numerable, standardized process and have matured through the test of practice. Exception knowledge refers to a kind of personal technical skill, experience knowledge which has not rules or is difficult to encode only happening in emergencies.

The institution of knowledge document accumulation and update refers to enterprise's professional knowledge managers organize technical skill, best practice and sorting into writing material, organize the enterprise strategy and good marketing methods and technology into become materials, then classify and keep in the archives, it can be shared for enterprise employees. The institution of updating knowledge document refers that the knowledge manager reviews the archived files in regulated time to see whether the contents are outdated, invalid, multiple and conflict.

The institution of the internalization of external knowledge refers to transform the knowledge of external experts and scholars into the enterprise's internal knowledge.

The institution of intellectual property rights protection refers to protect the knowledge staff's tacit knowledge property rights, establishing a series of protected measures including knowledge signature, intellectual achievements declaration, knowledge performance rewards and punishments etc. The intellectual property protection system can eliminate the knowledge staff's scary mind for losing some advantage status because of sharing tacit knowledge, coordinate tacit knowledge communication and the conflict of interest between owners and users during the sharing process, and change the monopoly tacit knowledge status into sharing with each others. 


\section{Tacit Knowledge Management Systems Implementation}

$\mathrm{X}$ company achieves the tacit knowledge management through building the sharing enterprise culture, constructing the effective incentive mechanism of the tacit knowledge sharing, optimizing and designing organization structure.

\subsection{Building Sharing Enterprise Culture}

Cultivates sharing type enterprise culture within X company mainly has the following steps: 1) Enterprise senior leaders' attention and participation. Enterprise senior leaders' attention can build a good atmosphere, that senior leaders participate and take the leading support and promote the sharing type culture construction can have example effectiveness; 2) Cultivate employees sharing values and team spirit. Team spirit emphasize the important position the team in the enterprise, it makes the employees to share experience and knowledge. The mutual cooperation among the members of the group can promote the transition of tacit knowledge; 3) Create a kind organization environment of sharing and innovating knowledge can be respected. Pay much attention and encouragement to the employee's knowledge sharing behavior, let employees contribute positive their knowledge in strong sharing type culture atmosphere for the organization; 4) Establish the corresponding knowledge incentive mechanism. Establish explicit knowledge system, make explicit the employee's knowledge achievement; establish a knowledge performance mechanism, the objective evaluation standards and knowledge reward mechanism, reward contributed employees; 5) Build learning organization. Train the knowledge staff continuing learning spirit.

\subsection{Construct Effective Incentive Mechanism}

$\mathrm{X}$ company establishes the effective incentive mechanism mainly in the following: 1) Build an incentive mechanism with the center of the knowledge staff's human capital property rights. The incentive mechanism with the center of the knowledge staff's human capital is as follow: a) incentive mechanism of tacit knowledge property rights; b) incentive mechanism of fully authorized; c) incentive mechanism of comprehensive salary. 2) Build an incentive mechanism with the center of self development. It includes: a) pay attention to the knowledge staff's individual development; b) give challenging work; c) strengthen the education training. 3) Build an incentive mechanism with the center of psychological contract. The psychological contract can create a "hidden platform” for enterprise's tacit knowledge transition and sharing.

\subsection{Design Organization Structure}

\subsubsection{Overlapping Principle}

That conscious overlap enterprise information, business activities and management responsibilities in the process of organizational structure design seems to mean unnecessary waste, but overlapping design can stimulate frequent dialogue and communication between enterprise employees, it can help staff to form a "common cognitive basis”, and also promote the individual tacit knowledge innovate into explicit knowledge.

\subsubsection{The Learning Principles}

Enterprise organization structure should create a good organizational environment for the employees' learn, and guide the staff systematic learn actively, so that employees can systematic study and think, and integrate the scattered knowledge resource dispersed in each staff's brain into a strong power. It can achieve a great purpose which acquires knowledge and information from others. It is more important to activate employee's knowledge innovative capability with learn.

\subsubsection{The Principles of Matching Power and Knowledge Distribution}

While running the knowledge management within enterprise, personal value and influence depends more on both how much the knowledge he owns and knowledge innovation capability, not the position, that is the principles of matching decision-making according with knowledge.

The implementation of X company organization structure optimum design includes as follow: 1) Establish a knowledge-based cooperation team. 2) Establish Chief Knowledge Officer. 3) Establish overlapping project develop teams.

\section{Tacit Knowledge Management Systems Evaluation}

There are nine questions in tacit knowledge and knowledge conversion (TKMS) [4]: 1) What is the status of "truth" in the definition of knowledge? 2) Do tacit and explicit knowledge fall along a continuum? 3) Is the tacit/explicit knowledge distinction along the continuum valuable for organization science? 4) What is the conceptual basis of knowledge conversion? 5) Given the relationship between tacit knowledge and social practices, how can the concept of knowledge conversion be upheld? 6) What is the outcome of knowledge conversion? 7) What is the relationship between organizational knowledge creation and social practices in organizations? 8) When and why do social practices contribute to the conservation of existing tacit knowledge and existing routine rather than organizational knowledge creation and innovation? 9) How can leadership motivate and enable individuals to contribute to organizational knowledge crea- 
tion by transcending social practices?

In our understanding, $\mathrm{X}$ company tacit knowledge management system mainly involves recognition and acquirement of tacit knowledge, conversion, sharing and implementation. It can take the three key indicators (critical success factors) for evaluation. The typical experts within $\mathrm{X}$ company give the evaluated score of every project according to the evaluation standard in Table 2.

Table 2. The critical success factors of tacit knowledge management system.

\begin{tabular}{|c|c|c|}
\hline Number & Index & Level (description) \\
\hline \multirow{5}{*}{$\mathrm{U}_{11}$} & \multirow{5}{*}{$\begin{array}{l}\text { The classified degree of tacit } \\
\text { knowledge }\end{array}$} & V1: Tacit knowledge hasn’t classified \\
\hline & & V2: Tacit knowledge has preliminary classified \\
\hline & & V3: Tacit knowledge has classified, but not refining \\
\hline & & V4: Tacit knowledge has classified and preliminary refining \\
\hline & & V5: Tacit knowledge has classified and refining completely \\
\hline \multirow{5}{*}{$\mathrm{U}_{12}$} & \multirow{6}{*}{$\begin{array}{l}\text { The perfect degree of the knowledge } \\
\text { structure chart }\end{array}$} & V1: Having basic classification for enterprise knowledge \\
\hline & & V2: Building the basic knowledge structure chart, but not perfect \\
\hline & & V3: Building the basic knowledge structure chart and basic perfect \\
\hline & & V4: Building the better perfect knowledge structure chart \\
\hline & & V5: Building a perfect knowledge structure chart \\
\hline \multirow{5}{*}{$\mathrm{U}_{13}$} & & V1: Basically not be used \\
\hline & \multirow{4}{*}{$\begin{array}{l}\text { The utilized efficiency of expert } \\
\text { knowledge map }\end{array}$} & V2: Low utilization rate \\
\hline & & V3: Middle utilization rate \\
\hline & & V4: Always be used \\
\hline & & V5: High utilization rate \\
\hline \multirow{5}{*}{$\mathrm{U}_{14}$} & \multirow{5}{*}{$\begin{array}{l}\text { The acquisitive standard of tacit } \\
\text { knowledge }\end{array}$} & V1: Very low \\
\hline & & V2: Low \\
\hline & & V3: Normal \\
\hline & & V4: High \\
\hline & & V5: Very high \\
\hline \multirow{5}{*}{$\mathrm{U}_{21}$} & \multirow{5}{*}{$\begin{array}{l}\text { The unblocked standard of the ways of } \\
\text { tacit knowledge sharing channels }\end{array}$} & V1: Not building the tacit knowledge sharing channels \\
\hline & & V2: Preliminary building the tacit knowledge sharing channels \\
\hline & & V3: Having build the tacit knowledge sharing channels \\
\hline & & V4: Having build a unblocked tacit knowledge sharing channels \\
\hline & & V5: Having build a very unblocked tacit knowledge sharing channels \\
\hline \multirow{5}{*}{$\mathrm{U}_{22}$} & \multirow{5}{*}{$\begin{array}{c}\text { The perfect degree of the technological } \\
\text { platform }\end{array}$} & V1: Enterprise only have internal LAN connection \\
\hline & & V2: Basic information network platform has been established \\
\hline & & V3: Having build the technology platform \\
\hline & & V4: Technological platform has basically perfected \\
\hline & & V5: Technological platform has perfected \\
\hline \multirow{5}{*}{$\mathrm{U}_{23}$} & \multirow{5}{*}{$\begin{array}{l}\text { The perfect standard of tacit } \\
\text { knowledge sharing mechanism }\end{array}$} & V1: Not building the sharing mechanism \\
\hline & & V2: Starting building the sharing mechanism \\
\hline & & V3: Having build the sharing mechanism \\
\hline & & V4: Having a basically perfect sharing mechanism \\
\hline & & V5: Having a perfect sharing mechanism \\
\hline \multirow{5}{*}{$\mathrm{U}_{31}$} & \multirow{6}{*}{$\begin{array}{l}\text { The building standard of sharing } \\
\text { enterprise culture }\end{array}$} & V1: No knowledge communication and sharing between employees \\
\hline & & V2: Start building knowledge-oriented enterprise culture \\
\hline & & V3: Having build, but not being received by employees \\
\hline & & V4: Having build and starting being received by employees \\
\hline & & V5: Having being received completely by employees and thick sharing atmosphere \\
\hline \multirow{5}{*}{$\mathrm{U}_{32}$} & & V1: Not building the incentive mechanism \\
\hline & \multirow{4}{*}{$\begin{array}{l}\text { The perfect degree of the effective } \\
\text { incentive mechanism of knowledge staff }\end{array}$} & V2: Having build the incentive mechanism, but not perfect \\
\hline & & V3: Having build basically the incentive mechanism \\
\hline & & V4: Having build the incentive mechanism \\
\hline & & V5: Having build a perfect incentive mechanism \\
\hline \multirow{5}{*}{$\mathrm{U}_{33}$} & \multirow{5}{*}{$\begin{array}{l}\text { The support strength of organizational } \\
\text { structure design }\end{array}$} & V1: Very low \\
\hline & & V2: Low \\
\hline & & V3: Normal \\
\hline & & V4: High \\
\hline & & V5: Very high \\
\hline
\end{tabular}


The capability of tacit knowledge acquisition and recognition $\left(\mathrm{U}_{1}\right)$ : The acquisition and recognition of tacit knowledge are mainly based on the effective classification for enterprise's tacit knowledge with constructing enterprise knowledge structure chart and expert knowledge map. It can use four secondary indicators to evaluate: The classified degree of tacit knowledge $\left(U_{11}\right)$, the perfect degree of the knowledge structure chart $\left(\mathrm{U}_{12}\right)$, the utilized efficiency of expert knowledge map $\left(U_{13}\right)$ and acquisitive standard of tacit knowledge $\left(\mathrm{U}_{14}\right)$.

The sharing standard of tacit knowledge $\left(\mathrm{U}_{2}\right)$ : it refers to break the barrier situation leaded by dividing the work by functions and bad internal competitive atmosphere, and sharing individual tacit knowledge with other knowledge individuals with the enterprise employees' continuous interaction and communication between each other. It can use three secondary indicators to evaluate as follows: the unblocked standard of the ways of tacit knowledge sharing channels $\left(\mathrm{U}_{21}\right)$, the perfect degree of the technological platform $\left(U_{22}\right)$ and the perfect standard of tacit knowledge sharing mechanism $\left(\mathrm{U}_{23}\right)$.

The realizing capability of tacit knowledge management $\left(\mathrm{U}_{3}\right)$ : It evaluates the details of implementation of tacit knowledge management. It can use three secondary indicators to evaluate, that is the building standard of sharing enterprise culture $\left(U_{31}\right)$, the perfect degree of the effective incentive mechanism of knowledge staff $\left(\mathrm{U}_{32}\right)$, the support strength of organizational structure design $\left(\mathrm{U}_{33}\right)$.

\section{Conclusion}

Case study for the tacit knowledge and its transition within X company is carried out. The knowledge conversion technology, the tacit knowledge management system, the mechanism of knowledge conversion and the resistance during the knowledge conversion have been analyzed, it provides a reference for realizing successfully tacit knowledge management system. The evaluation system based on critical success factors is put forward. Of course, it is only qualitative analysis on the views of influential factors, process and significance of conversion for TKMS. The specific methods, steps and corresponding evaluation system of conversion remain to be further researched and discussed.

\section{REFERENCES}

[1] M. Polanyi, "Personal Knowledge," University of Chicago Press, Chicago, 1958.

[2] V. Allee, “The Knowledge Evolution: Expanding Organizational Intelligence,” Butterworth Heinemann, Boston, 1997.

[3] I. Nonaka, "The Knowledge Creating Company," Harvard Business Review, Vol. 69, No. 6, 1991, pp. 96-104.

[4] I. Nonaka and G. V. Krogh, "Perspective-Tacit Knowledge and Knowledge Conversion: Controversy and Advancement in Organizational Knowledge Creation Theory,” Organization Science, Vol. 20, No. 3, 2009, pp. 635-652. doi:10.1287/orsc.1080.0412

[5] J. P. Wan, Q. J. Liu, D. J. Li and H. B. Xu, "Research on Knowledge Transfer Influencing Factors in Software Process Improvement," Journal of Software Engineering and Applications, Vol. 3, No. 2, 2010, pp. 134-140. doi:10.4236/jsea.2010.32017

[6] J. P. Wan, H. Zhang, D. Wan and D. Y. Huang, "Research on Knowledge Creation in Software Requirement Development," Journal of Software Engineering and Applications, Vol. 3, No. 5, pp. 487-494.

[7] J. P. Wan and R. Wang, "The Exploratory Analysis on Knowledge Creation Effective Factors in Software Requirement Development,” Journal of Software Engineering and Applications, Vol. 3, No. 6, 2010, pp. 580-587. doi:10.4236/jsea.2010.36067

[8] J. P. Wan, D. Wan, W. P. Luo and X. Y. Wan, "Research on Explicit and Tacit Knowledge Interaction in Software Process Improvement Project," Journal of Software Engineering and Applications, Vol. 4, No. 6, 2011, pp. 335344. doi:10.4236/jsea.2011.46038

[9] G. Anand, P. T. Ward and M. V. Tatikonda, "Role of Explicit and Tacit Knowledge in Six Sigma Projects: An Empirical Examination of Differential Project Success," Journal of Operations Management, Vol. 28, No. 4, 2010, pp. 303-315. doi:10.1016/j.jom.2009.10.003 